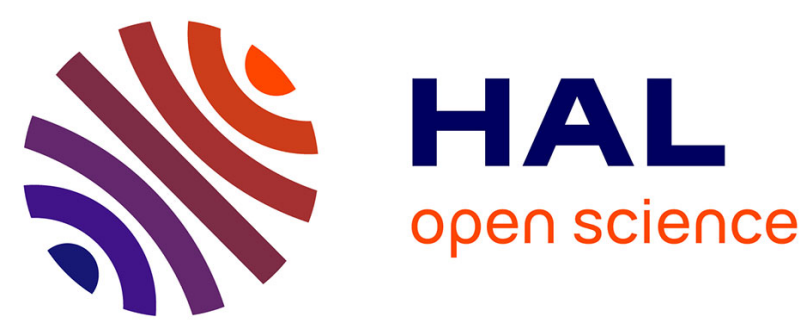

\title{
Retinal vascular caliber associated with cardiac and renal target organ damage in never-treated hypertensive patients
}

Vincent Daien, Loic Granados, Ryo Kawasaki, Max Villain, Jean Ribstein, Guilhem Du Cailar, Albert Mimran, Pierre Fesler

\section{To cite this version:}

Vincent Daien, Loic Granados, Ryo Kawasaki, Max Villain, Jean Ribstein, et al.. Retinal vascular caliber associated with cardiac and renal target organ damage in never-treated hypertensive patients. Microcirculation, 2017, 24 (4), 10.1111/micc.12344 . hal-01794203

\section{HAL Id: hal-01794203 \\ https://hal.science/hal-01794203}

Submitted on 16 Dec 2019

HAL is a multi-disciplinary open access archive for the deposit and dissemination of scientific research documents, whether they are published or not. The documents may come from teaching and research institutions in France or abroad, or from public or private research centers.
L'archive ouverte pluridisciplinaire HAL, est destinée au dépôt et à la diffusion de documents scientifiques de niveau recherche, publiés ou non, émanant des établissements d'enseignement et de recherche français ou étrangers, des laboratoires publics ou privés. 


\title{
Retinal vascular caliber associated with cardiac and renal target organ damage in never-treated hypertensive patients
}

\author{
Vincent Daien $^{1,2,3}$ | Loic Granados ${ }^{1,2}$ | Ryo Kawasaki ${ }^{4}$ | Max Villain ${ }^{1,2}$ | \\ Jean Ribstein $^{2,5}$ | Guilhem Du Cailar ${ }^{5}$ | Albert Mimran ${ }^{5}$ | Pierre Fesler 2,5,6
}

\author{
${ }^{1}$ Department of Opthalmology, Hôpital Gui de \\ Chauliac, Montpellier, France \\ ${ }^{2}$ Université Montpellier 1, Montpellier, France \\ ${ }^{3}$ National Institute for Health and Medical \\ Research (INSERM), U1061, Montpellier, \\ France \\ ${ }^{4}$ Department of Public Health, Yamagata \\ University Graduate School of Medical \\ Science, Yamagata, Japan \\ ${ }^{5}$ Department of Internal Medicine, Hôpital \\ Lapeyronie, Montpellier, France \\ ${ }^{6}$ PhyMedExp, INSERM U1046, CNRS UMR \\ 9214, University of Montpellier, 34295 \\ Montpellier Cedex 5, France

\section{Correspondence} \\ Vincent Daien, Service d'ophtalmologie, \\ Hôpital Gui de Chauliac, Montpellier, France. \\ Email:v-daien@chu-montpellier.fr
}

\begin{abstract}
Objective: The aim of this study was to assess the relationship between retinal vascular caliber and target organ damage in HT patients.

Methods: Data were collected on cardiac, renal, vascular, and retinal variables in 88 consecutive never-treated HT subjects. Retinal vascular calibers were measured from fundus photographs by using a semi-automated computer-assisted program and summarized as CRAE and CRVE.

Results: Mean CRAE and CRVE were significantly lower in patients with left ventricular hypertrophy (left ventricular mass $\geq 110 \mathrm{~g} / \mathrm{m}^{2}$ for women, $125 \mathrm{~g} / \mathrm{m}^{2}$ for men) than in those with normal left ventricular (CRAE: $129.4 \pm 3.7$ vs 138.2 $\pm 2.3 \mu \mathrm{m} ; P=.04$; CRVE: 195.6 \pm 4.4 vs $209.8 \pm 2.7 \mu \mathrm{m} ; P=.008)$. CRAE and CRVE were negatively correlated with urinary albumin excretion $(\beta \pm S E=-15.4 \pm 3.2, P<.0001$ and $\beta \pm S E=-11.9 \pm 4.4$, $P=.001$, respectively) but were not correlated with estimated glomerular filtration rate $(P=.21$ and $P=.75$, respectively), carotid-to-femoral pulse wave velocity $(P=.24$ and $P=.14)$, or carotid augmentation index $(P=.43$ and $P=.16)$.
\end{abstract}

Conclusion: In never-treated HT patients, reduced CRAE and CRVE were associated with cardiac and renal preclinical damage, ie, left ventricular hypertrophy and albuminuria, but not estimated glomerular filtration rate or vascular stiffness.

\section{KEYWORDS}

hypertension, microcirculation, retinal vessels, target organ damages

\section{1 | INTRODUCTION}

$\mathrm{CV}$ risk in $\mathrm{HT}$ patients is strongly associated with the presence of early changes in organ systems in the body, grouped under the term TOD, such as $\mathrm{LVH}^{1,2}$ albuminuria, ${ }^{3-5}$ decreased GFR, ${ }^{6-8}$ retinopathy, ${ }^{9-12}$ vascular stiffening, ${ }^{13,14}$ or cerebral white matter lesions. ${ }^{15,16}$

\footnotetext{
Abbreviations: Alx, augmentation index; $\mathrm{AP}$, augmented pressure; ARIC, atherosclerosis risk in communities; $\mathrm{BP}$, blood pressure; $\mathrm{Cl}$, confidence interval; $\mathrm{CKD}$, chronic kidney disease; CRAE, central retinal artery equivalent; CRVE, central retinalvein equivalent; CV, cardiovascular; GFR, glomerular filtration rate; HT, hypertensive; LVH, left ventricular hypertrophy; LV, left ventricular; LVM, left ventricular mass; MESA, multiethnic study of atherosclerosis; PWT, posterior wall thickness; RWT, relative wall thickness; TOD, target organ damage.
}

Meta-analyses of epidemiological studies revealed wide retinal venules and narrow arterioles associated with increased risk of coronary heart disease in women and increased risk of global CV mortality; ${ }^{17}$ wide retinal venular caliber predicted stroke. ${ }^{17-19}$ In HT, both $\mathrm{LVH}$ and renal function are excellent independent CV event predictors. ${ }^{20}$ Assessment of retinal microcirculation may help with investigating $\mathrm{CV}$ and renal damage.

Generalized and focal retinal arteriolar narrowing is associated with $\mathrm{LVH}^{21}$ The MESA found LVH and LV concentric remodeling associated with narrow retinal arterioles and retinopathy in men and women. ${ }^{22}$

In patients with renal failure, retinal arteriolar and venular caliber progressively decrease with increasing stage of CKD. In patients with 
CKD stage 2-4, presence of small retinal arterioles and increased microalbuminuria was correlated with decreased rate GFR. ${ }^{23,24}$ In healthy subjects, narrow arterioles and veins were associated with decreased GFR and small arteriolar diameter with increased albuminuria. ${ }^{25}$

Fundus photography provides a noninvasive approach to assess retinal microcirculation. Changes in caliber of retinal vessels can reflect the cumulative effects of birth weight, ${ }^{26,27}$ body mass index, ${ }^{28} \mathrm{CV}$ risk factors, ${ }^{29,30}$ renal function, ${ }^{25}$ inflammation, ${ }^{31}$ oxidative stress, ${ }^{32}$ and genetic factors. ${ }^{33}$

Arteriolar narrowing may be associated with other markers of TOD in uncontrolled $\mathrm{HT}^{34-36}$ However, we lack evidence of the additional benefit of assessing retinal vascular caliber to identify TOD in patients with early $\mathrm{HT}^{37,38}$ Here, we aimed to assess whether a decrease in retinal vessel caliber was associated with other preclinical TOD in nevertreated HT patients.

\section{PATIENTS AND METHODS}

This paper followed the STROBE checklist items for reporting crosssectional study. ${ }^{39}$

\section{1 | Setting}

Subjects were recruited from the outpatient clinic of the Department of Medicine of University Hospital, Montpellier, France.

\section{2 | Participants}

The study population consisted of 88 consecutive never-treated hypertensive subjects. The subjects presented or were referred by general practitioners for detecting or investigating $\mathrm{CV}$ risk factors through a local screening program for $\mathrm{CV}$ risk.

We considered only HT patients without other known CV, renal, or metabolic disease and who had never received antihypertensive, antidiabetic or lipid-lowering therapy. Patients were excluded if they had clinical evidence of atherosclerosis (stroke or coronary and peripheral artery disease), heart failure, renal failure (serum creatinine level $>1.2 \mathrm{mg} / \mathrm{dL}$ ), diabetes mellitus (fasting blood glucose $>126 \mathrm{mg} / \mathrm{dL}$ ), obesity (body mass index $>30 \mathrm{~kg} / \mathrm{m}^{2}$ ), history of alcohol abuse ( $>5$ drinks/day), or secondary HT.

Written informed consent was obtained from each participant in adherence to the provisions of the 1995 Declaration of Helsinki (revised in 2000). This study was approved by the University Hospital of Montpellier.

\section{3 | Study design}

This was a cross-sectional study of data from a prospectively designed observational study.

\subsection{1 | Blood pressure}

BP was measured every 3 min with the use of an automatic device (Model Dinamap V100; GE Healthcare, Little Chalfont, UK), and reported values are the average of at least 10 measurements following a 10 -min period of rest in the supine position. Mean blood pressure was calculated as systolic BP $+\left[2^{*}\right.$ diastolic BP] / 3. HT was defined as systolic BP $\geq 140 \mathrm{~mm} \mathrm{Hg}$ and/or diastolic BP $\geq 90 \mathrm{~mm} \mathrm{Hg}$ (International Society of Hypertension Guidelines 1999).

\subsubsection{Determination of renal function}

On the day of investigation, patients came to the ward with a 24-h urine collection to determine urinary albumin excretion (UAE: organ damage significance level set to $\geq 10 \mathrm{mg} / 24 \mathrm{~h}$, a cutoff value obtained in a previous local sample of normal subjects with $\mathrm{BP}<140 / 90 \mathrm{~mm} \mathrm{Hg}$ ) and levels of creatinine, urea (index of protein intake), electrolytes, sodium (index of sodium intake), and potassium. Prior to investigations, subjects were measured for weight (Model 703; CKSeca, Hamburg, Deutschland) and height (Microtoise 04-116; Stanley Black \& Decker, New Britain, CT, USA). Fasting blood samples were obtained to measure serum creatinine level (IDMS enzymatic method), glucose, electrolytes, total cholesterol, triglycerides, and lipid levels.

\subsection{3 | Echocardiographic parameters}

Echocardiographic assessment of LV morphology was performed by the same observer (GDC) using the SC2000 ultrasound system (Siemens, Mountain View, CA, USA) with a 2.5- or 3.5-MHz transducer. Technical details were reported elsewhere. ${ }^{40}$

LVM was estimated from end-diastolic LV diameter, interventricular septum thickness, and PWT according to the Devereux formula, using the Penn convention. ${ }^{41}$ LVM was normalized to body surface area to obtain the LVM index (LVMI, $\left.\mathrm{g} / \mathrm{m}^{2}\right)$. RWT was calculated as follows:

$\mathrm{RWT}=\frac{(2 * \mathrm{PWd})}{\text { LVEDD }}$ PWd: PWT at end-diastole $(\mathrm{mm})$

LVEDD: LV end-diastolic dimension ( $\mathrm{mm}$ )

The presence of LVH was defined as LVMI $\geq 125 \mathrm{~g} / \mathrm{m}^{2}$ for men and $110 \mathrm{~g} / \mathrm{m}^{2}$ for women. A concentric pattern was defined as RWT $\geq 0.44$. These cutoff values were obtained in a previous local sample of normal subjects with $\mathrm{BP}<140 / 90 \mathrm{~mm} \mathrm{Hg}$.

To evaluate the association between cardiorenal damage and changes in retinal vessel diameters induced by $\mathrm{HT}$, we created four TOD groups as follows:

- TOD 1. Normal LVMI and UAE $\leq 10 \mathrm{mg} / 24 \mathrm{~h}$

- TOD 2. LVH and UAE $\leq 10 \mathrm{mg} / 24 \mathrm{~h}$

- TOD 3. Normal LVMI and UAE $>10 \mathrm{mg} / 24 \mathrm{~h}$

- TOD 4. LVH and UAE >10 mg/24 h

\subsection{4 | Retinal vascular caliber measurements}

Retinal photographs of both eyes were obtained by using a nonstereoscopic, $45^{\circ}$ nonmydriatic fundus camera (CR5-NM45; Canon

All patients underwent the following procedures on the same day. 
Inc., Tokyo, and TRC, Topcon Inc., Tokyo) centered on the optical disk. Diameters of all vessels in a specified area (0.5-1 disk diameter surrounding the optic disk) were measured by using image analysis software (IVAN, Department of Ophthalmology Visual Science, University of Wisconsin, Madison, WI). The caliber of the central retinal artery and vein was estimated by using the "Big- 6 formula" and summarized as CRAE and CRVE. ${ }^{42,43}$ The reproducibility of retinal vascular measurements was high, with intraobserver correlation coefficients of 0.97 [95\% Cl: $0.96-0.98]$ and $0.95(95 \% \mathrm{Cl}$ : 0.94-0.96) for CRAE and CRVE, respectively. With the high intereye correlation reported in previous studies, ${ }^{44}$ we analyzed only one eye per subject (the right eye, or, if unavailable or not gradable, the left eye).

\subsection{5 | Vascular stiffness variables}

\section{Pulse wave velocity}

Femoral, carotid, and radial pressure waveforms were recorded by applanation tonometry by using the SphygmoCor system (AtCor Medical, Sidney, Australia). From carotid and femoral waveforms, wave transit time was calculated with the $\mathrm{R}$ wave of a simultaneously recorded electrocardiogram used as a reference frame and the foot of the waves determined with an intersecting tangent algorithm. Distances from the suprasternal notch to carotid and femoral sites were measured, and transit distance was calculated by subtracting the two distances, thus allowing for correction of parallel transmission. Carotid-to-femoral pulse wave velocity (PWV) was then calculated as transit distance divided by transit time. ${ }^{45}$

\section{Pulse wave analysis}

Carotid pressure waveform was used to estimate central aortic waveform without the use of a transfer function. Carotid pressure waveform was calibrated by using mean and diastolic pressure values of the radial pressure waveform, which was itself calibrated with cuffmeasured systolic and diastolic brachial BP. AP was determined as the pressure difference between the first and second peaks of carotid waveform. The carotid Alx was calculated as AP/central pulse pressure. ${ }^{46}$ As evaluated by Wilkinson et al. ${ }^{47}$ and with Bland-Altman plots, within-observer variability is $0.07 \pm 1.17 \mathrm{~m} / \mathrm{sec}$ for carotid-tofemoral PWV and $0.49 \pm 5.37 \%$ for Alx.

\section{5 | Statistical analysis}

SAS v9.4 (SAS Inst., Cary, NC, USA) was used for data analysis. Because of their skewed distribution, urinary albumin values were log-transformed before analysis. The relationship between retinal variables and age, gender, mean BP, and BMI was first tested by linear univariate analysis and then by multivariate linear regression to detect the independent relationship between retinal, vascular, and renal variables. Analysis of covariance (ANCOVA) was used to determine the association of retinal vascular caliber and cardiac patterns and TOD adjusted for age, sex, BP and BMI, smoking status, total cholesterol, triglyceride levels, and fasting blood glucose.
Post hoc pairwise comparisons were corrected for multiple testing by using the Tukey-Kramer method.

Unless otherwise stated, results are expressed as mean \pm SD or median (interquartile range) for descriptive statistics and mean $\pm \mathrm{SE}$ for results of multivariate analysis. Significance was set at $P<.05$.

\section{3 | RESULTS}

\section{1 | Population characteristics}

The study population consisted of 88 never-treated hypertensive subjects ( 38 women, mean \pm SD age $54 \pm 11$ years; range 32 83 years) (Table 1). Mean systolic BP was $155 \pm 15 \mathrm{~mm} \mathrm{Hg}$ and diastolic BP $89 \pm 10 \mathrm{~mm} \mathrm{Hg}$. Mean RWT was 0.46 and LVMI $115 \pm 24 \mathrm{~g} / \mathrm{m}^{2}$. Average eGFR was $97.6 \pm 22.4 \mathrm{~mL} / \mathrm{min} / 1.73 \mathrm{~m}^{2}$, serum creatinine level $98 \pm 22 \mu \mathrm{m} / \mathrm{L}$, and median (interquartile range) UAE (5.35 [3.47-9.56] $\mu \mathrm{g} / \mathrm{min})$. Mean CRAE was $136 \pm 18 \mu \mathrm{m}$ and CRVE $205 \pm 21 \mu \mathrm{m}$. Mean PWV was $9.9 \pm 2.5 \mathrm{~m} / \mathrm{sec}$ and carotid Alx $32 \pm 10 \%$. In this population of hypertensive subjects, 23 (26.1\%) had LVH (LVMI $\geq 125 \mathrm{~g} / \mathrm{m}^{2}$ for men and $110 \mathrm{~g} / \mathrm{m}^{2}$ for women) and $18(20.5 \%)$ had $U A E \geq 10 \mathrm{mg} / 24 \mathrm{~h}$.

TABLE 1 Characteristics of 88 patients with never-treated hypertension

\begin{tabular}{|c|c|}
\hline Age (year) & $54 \pm 11$ \\
\hline Male (\%) & 56.8 \\
\hline Current smoker (\%) & 18.5 \\
\hline $\mathrm{BMI}\left(\mathrm{kg} / \mathrm{m}^{2}\right)$ & $26.49 \pm 4.66$ \\
\hline Systolic BP (mm Hg) & $155 \pm 15$ \\
\hline Diastolic BP (mm Hg) & $89 \pm 10$ \\
\hline Mean BP (mm Hg) & $111 \pm 10$ \\
\hline Fasting blood glucose (mmol/L) & $5.02 \pm 0.6$ \\
\hline Hba1c (\%) & $5.56 \pm 0.45$ \\
\hline Total cholesterol (mmol/L) & $2.20 \pm 0.35$ \\
\hline HDL cholesterol (mmol/L) & $0.6 \pm 0.2$ \\
\hline Calculated LDL cholesterol (mmol/L) & $1.31 \pm 0.3$ \\
\hline Triglycerides (mmol/L) & $1.2 \pm 0.7$ \\
\hline eGFR (mL/min/1.73 $\left.\mathrm{m}^{2}\right)$ & $97.6 \pm 22.4$ \\
\hline Serum creatinine level $(\mu \mathrm{mol} / \mathrm{L})$ & $98 \pm 22$ \\
\hline Urinary albumin excretion (mg/min) & $5.35(3.47-9.56)$ \\
\hline LVMI $\left(\mathrm{g} / \mathrm{m}^{2}\right)$ & $115 \pm 24$ \\
\hline RWT & $0.46 \pm 0.1$ \\
\hline Femoral PWV (m/s) & $9.9 \pm 2.5$ \\
\hline Carotid Alx & $32 \pm 10$ \\
\hline CRAE $(\mu \mathrm{m})$ & $136 \pm 17.7$ \\
\hline CRVE $(\mu \mathrm{m})$ & $205.6 \pm 20.8$ \\
\hline
\end{tabular}

Data are mean \pm standard deviation or median (interquartile range). BP, blood pressure; eGFR, estimated glomerular filtration rate; LV, left ventricular; HDL, high-density lipoprotein; LDL, low-density lipoprotein; PWV, pulse wave velocity; Alx, augmentation index; LVMI, left ventricular mass index; RWT, relative wall thickness; CRAE, central retinal artery equivalent; CRVE, central retinal vein equivalent; $A V R$, retinal artery/vein ratio. 
TAB LE 2 Association of retinal caliber with cardiac morphology patterns (LV hypertrophy, concentric pattern)

\begin{tabular}{|c|c|c|c|c|c|c|c|c|c|}
\hline & & \multicolumn{4}{|l|}{ CRAE $(\mu \mathrm{m})$} & \multicolumn{4}{|l|}{ CRVE $(\mu \mathrm{m})$} \\
\hline & & \multicolumn{2}{|l|}{ Crude } & \multicolumn{2}{|l|}{ Adjusted $^{a}$} & \multicolumn{2}{|l|}{ Crude } & \multicolumn{2}{|l|}{ Adjusted $^{a}$} \\
\hline & & & $P$ & & $P$ & & $P$ & & $P$ \\
\hline \multirow[t]{2}{*}{ LV hypertrophy } & Increased LVMI & $129.6 \pm 3.5$ & .03 & $129.4 \pm 3.7$ & .04 & $196.5 \pm 4.1$ & .01 & $195.6 \pm 4.4$ & .008 \\
\hline & Normal LVMI & $138.4 \pm 2.2$ & & $138.2 \pm 2.3$ & & $208.9 \pm 2.5$ & & $209.8 \pm 2.7$ & \\
\hline \multirow{2}{*}{$\begin{array}{l}\text { LV concentric } \\
\text { pattern }\end{array}$} & RWT $\geq 0.44$ & $135.4 \pm 2.8$ & .87 & $136.7 \pm 2.7$ & .61 & $205.6 \pm 3.3$ & .91 & $205.6 \pm 3.8$ & .92 \\
\hline & RWT $<0.44$ & $136.4 \pm 2.6$ & & $134.6 \pm 2.5$ & & $205.5 \pm 3$ & & $205.3 \pm 3.1$ & \\
\hline
\end{tabular}

Data are mean \pm standard error. LV, left ventricle; LVMI, left ventricular mass index; RWT, relative wall thickness; CRAE, central retinal artery equivalent; CRVE, central retinal vein equivalent; AVR, retinal artery/vein ratio.

${ }^{a}$ Adjusted on age, sex, body mass index, mean blood pressure, smoking status, total cholesterol (mmol/L), Triglycerides (mmol/L), and Fasting blood glucose $(\mathrm{mmol} / \mathrm{L})$

$b_{\geq} \geq 125 \mathrm{~g} / \mathrm{m}^{2}$ in men and $\geq 110 \mathrm{~g} / \mathrm{m}^{2}$ in women.

\subsection{Association of retinal caliber and LV geometry patterns}

Mean CRAE was significantly lower in patients with LVH than in those with normal LVMI (mean \pm SE $129.6 \pm 3.5$ vs $138.4 \pm 2.2 \mathrm{~g} / \mathrm{m}^{2}$; $P=.03$ ) and remained significant after adjustment on age, sex, BMI, mean BP smoking status, total cholesterol, triglyceride levels, and fasting blood glucose $\left(129.4 \pm 3.7\right.$ vs $138.2 \pm 2.3 \mathrm{~g} / \mathrm{m}^{2} ; P=.04$, Table 2). The same association was found for CRVE (196.5 \pm 4.1 vs $208.9 \pm 2.5 \mu \mathrm{m} ; P=.01)$ even after adjustment $(195.6 \pm 4.4$ vs $209.8 \pm 2.7 \mu \mathrm{m} ; P=.008)$.

\subsection{Association of renal function and retinal microvasculature}

After adjustment on age, sex, BMI, mean BP smoking status, total cholesterol, triglyceride levels, and fasting blood glucose, CRAE and CRVE were negatively correlated with $\mathrm{UAE}(\beta \pm \mathrm{SE}=-15.4 \pm 3.2 ; P<.001$; $\beta \pm S E=-11.9 \pm 4.4 ; P>001$, respectively, Table 3 ). eGFR was not correlated with retinal vessel variables.

\subsection{Association of retinal caliber and vascular stiffness}

CRAE and CRVE were negatively correlated with carotid-to-femoral PWV $(\beta \pm S E=-1.52 \pm 0.75, \quad P=.04$, and $\beta \pm S E=-1.81 \pm 0.88, \quad P=.04$, respectively) but not after adjustment on age, sex, BMI, mean BP smoking status, total cholesterol, triglyceride levels, and fasting blood glucose $(\beta \pm S E=-1.10 \pm 0.8 P=.24$, and $\beta \pm S E-1.68 \pm 1.09, P=.14$, respectively, Table 4).

\section{5 | Association of retinal caliber and combined cardiorenal damage}

About retinal caliber, adjusted CRAE was lower for TOD group 4 (LVH and high UAE), 3 (normal LVMI but high UAE), and 2 (LVH and normal UAE) than group 1 (normal LVMI and UAE) $(114.5 \pm 6.3,127.3 \pm 5.1$, and $134.2 \pm 4.2$ vs $140.7 \pm 2.4 \mu \mathrm{m}$, respectively; $P$ trend=.003) (Figure 1 ).
Similar results were observed for adjusted CRVE (181.5 \pm 8.4 , $202.2 \pm 6.3$, and $199.8 \pm 4.8$ vs $211.3 \pm 2.9 \mu \mathrm{m}$, respectively; $P$ trend $=.03$ ).

\section{4 | DISCUSSION}

In the present study of 88 never-treated HT subjects, reduced arteriolar and venular retinal caliber were associated with LVH and increased albuminuria but not concentric pattern of LV, eGFR or aortic stiffness, independent of mean BP, BMI, age, and sex.

Koren et al. observed that age and LVM were better predictors of CV morbidity/mortality than BP. In a 10-year follow-up study of 280 patients with uncomplicated $\mathrm{HT}$, those with normal LV geometry had fewer $\mathrm{CV}$ outcomes than those with concentric hypertrophy. ${ }^{2}$ Retinal vascular caliber has been associated with risk of $\mathrm{CV}$ mortality. ${ }^{17}$ Therefore, the relationship between retinal and cardiac modification in HT patients is of particular interest.

In the MESA study of 4593 patients from the general population, LVM (measured by MRI) was associated with narrow arterioles and retinopathy in both men and women. The relation between LVH and reduced vein diameter was significant only in women. ${ }^{22}$ In a subpopulation of 2622 African Americans from the ARIC study, LVM and CRAE were correlated: Increased LVM was associated with generalized and focal arteriolar narrowing but not retinopathy or arteriovenous crossing. ${ }^{21}$

In the present study, retinal arteriolar and venular caliber were significantly lower in subjects with LVH than in those with normal LV mass. However, in accordance with Cuspidi et al., ${ }^{48}$ we found no difference in retinal changes between subjects with normal LV pattern and those with LV concentric pattern.

The association between GFR or albuminuria and retinal vessel caliber is still unclear. In the ARIC study of a general population of 10056 people, serum creatinine level was not associated with retinal vascular diameter, but 6-year increase in serum creatinine level was correlated with decrease in CRAE and CRVE. ${ }^{49}$ In the Cardiovascular Health Study, the presence of retinopathy was associated with deteriorating renal function but not arteriolar diameter. ${ }^{50}$ However, in a cross-sectional study of 126 patients with incipient to severe CKD, 
TABLE 3 Multivariate analysis of renal outcome predictors of retinal vascular caliber

\begin{tabular}{|c|c|c|c|c|c|c|c|c|c|}
\hline & & \multicolumn{4}{|l|}{ CRAE } & \multicolumn{4}{|l|}{ CRVE } \\
\hline & & $\beta \pm S E$ & $P$ & $r^{2}$ & $P$ & $\beta \pm \mathrm{SE}$ & $P$ & $r^{2}$ & $P$ \\
\hline \multirow[t]{2}{*}{$\mathrm{UAE}(\mu \mathrm{g} / \mathrm{min}, \mathrm{Log})$} & Crude & $-14.7 \pm 3.3$ & $<.0001$ & & & $-9.6 \pm 3.7$ & .02 & & \\
\hline & Adjusted $^{a}$ & $-15.4 \pm 3.2$ & $<.0001$ & .29 & $<.0001$ & $-11.9 \pm 4.4$ & .001 & .11 & .04 \\
\hline \multirow[t]{2}{*}{ eGFR $(\mu \mathrm{mol} / \mathrm{L})$} & Crude & $0.07 \pm 0.08$ & .42 & & & $0.08 \pm 0.1$ & .43 & & \\
\hline & Adjusted $^{a}$ & $0.06 \pm 0.09$ & .57 & .06 & .21 & $0.05 \pm 0.1$ & .68 & .02 & .75 \\
\hline
\end{tabular}

Data are mean \pm standard error. UAE, urinary albumin excretion; eGFR, estimated glomerular filtration rate; CRAE: central retinal artery equivalent; CRVE, central retinal vein equivalent; AVR, retinal artery/vein ratio.

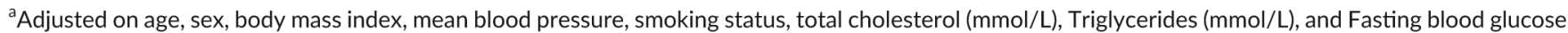
$(\mathrm{mmol} / \mathrm{L})$

TABLE 4 Multivariate analysis of vascular predictors of retinal vascular caliber

\begin{tabular}{|c|c|c|c|c|c|}
\hline & & \multicolumn{2}{|l|}{ CRAE } & \multicolumn{2}{|l|}{ CRVE } \\
\hline & & $\beta \pm S E$ & $P$ & $\beta \pm S E$ & $P$ \\
\hline \multirow{2}{*}{$\begin{array}{l}\text { Carotid-to-femoral } \\
\text { PWV }\end{array}$} & Crude & $-1.52 \pm 0.75$ & .04 & $-1.81 \pm 0.88$ & .04 \\
\hline & Adjusted $^{a}$ & $-1.10 \pm 0.8$ & .24 & $-1.68 \pm 1.09$ & .14 \\
\hline \multirow[t]{2}{*}{ Central Alx (AP/PP) } & Crude & $-0.04 \pm 0.19$ & .84 & $0.18 \pm 0.22$ & .43 \\
\hline & Adjusted $^{\mathrm{a}}$ & $0.19 \pm 0.20$ & .43 & $0.33 \pm 0.24$ & .16 \\
\hline
\end{tabular}

PWV, pulse wave velocity; AP, arterial pressure; PP, pulse pressure.

${ }^{a}$ Adjusted on age, sex, body mass index, mean blood pressure, smoking status, total cholesterol $(\mathrm{mmol} / \mathrm{L})$, Triglycerides (mmol/L), and Fasting blood glucose $(\mathrm{mmol} / \mathrm{L})$.

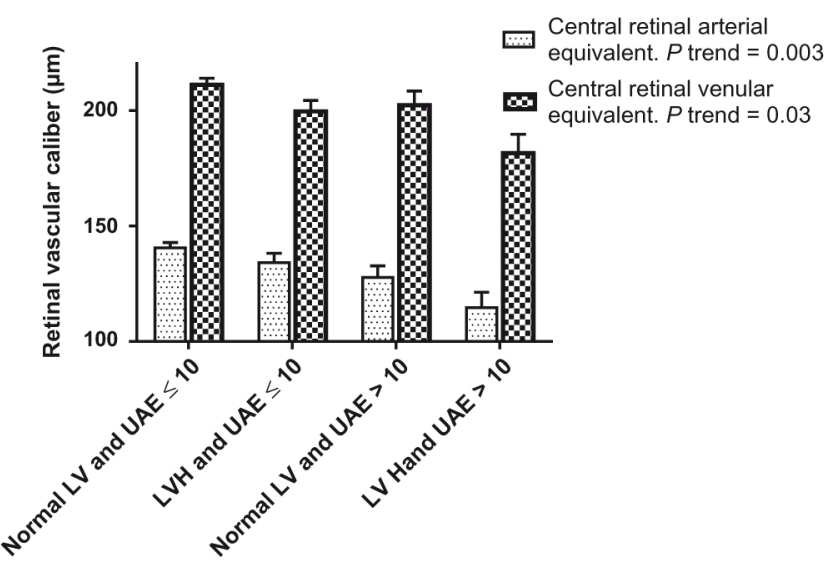

FIGURE 1 Comparison of CRAE and CRVE ( $\mu \mathrm{m})$ among four TOD groups, adjusted on age, sex, body mass index, mean blood pressure, smoking status, total cholesterol, triglyceride levels, and fasting blood glucose. Results are expressed as mean and $95 \%$ confidence interval

CRAE progressively decreased with increasing renal disease stage, and Sabanayagam et al. found CRAE independently related to decreased eGFR $<60 \mathrm{~mL} / \mathrm{min} / 1.73 \mathrm{~m}^{2}(P=.02)$ and increased albuminuria $(P=.01)$ in HT patients. ${ }^{23,51}$ Among healthy subjects, CRAE was related to measured GFR (urinary clearance of $99 \mathrm{mTc}$-DTPA) and albuminuria. ${ }^{25}$

In this study of HT patients, we found a close association between CRAE, CRVE, and UAE, considered as a marker of early kidney dysfunction, which may emphasize the role of the microvasculature in the pathogenesis of renal disease progression and the two vascular factors in predicting CKD and general CV events. However, a role for renal perfusion pressure and more specifically intraglomerular pressure on albuminuria cannot be excluded. In the present study, BP was negatively correlated with retinal arteriolar and venular size. The possibility exists that the response of arteriolar vessels represents an autoregulation process similar to that encountered in glomerular vessels of the kidney, aiming at protecting the kidney against the deleterious effects of intraglomerular hypertension. Other mechanisms can be raised in order to explain the relationship between GFR or albuminuria and retinal vascular calibers. Although microalbuminuria was proposed as a marker of insipient nephropathy in insulin-dependant diabetes, it was later associated with cardiovascular events reflecting systemic endothelial capillary damage with increased permeability. ${ }^{3}$

Hypertensive subjects show a progressive stiffening of the aorta that may occur in parallel with retinal vascular changes. Previous studies have found an association between reduced carotid-to-femoral PWV, a sign of aortic stiffening, and hypertensive retinopathy. ${ }^{52}$ In 2169 subjects from a general population, elevated brachial-ankle PWV was associated with narrow CRAE but not after adjustment. ${ }^{53}$ Recently, a comparison of 137 never-treated hypertensive patients and 83 healthy subjects revealed a significant inverse association between PWV and Alx with CRAE but not CRVE after adjustment on confounding factors. ${ }^{54}$ Our findings were consistent with the existing literature because we found a possible association between CRAE and PWV but not after adjustment on age, sex, BMI, and mean BP, which are strong confounding factors of vascular stiffness.

In the present study, retinal arterial and venular caliber were significantly reduced in patients with increased UAE or LVH and even more in patients with the presence of both TOD. Of note, UAE seemed 
to be more involved than LVH in arteriolar narrowing, whereas LVH was predominant on venular modifications.

The strengths of this study include the precise measurement of vascular caliber in never-treated HT subjects with no other known cardiovascular condition, thus avoiding the potential effect of antihypertensive drugs on renal, ${ }^{55}$ cardiac, vascular, and retinal microcirculation. ${ }^{56}$ Many studies point to the poor inter- and intraobserver reproducibility in grading retinopathy from direct fundoscopy or photography between Keith and Wagener grade I and II (about 80\% patients). ${ }^{57}$ However, our analysis of retinal vascular caliber was based on measurements showing high reproducibility.

The main limitation of this study was its cross-sectional nature that did not allow us to propose causal inferences such as the temporal sequence between altered retinal microcirculation and TOD. Also, the population size was small $(n=88)$. The results of the present study may be specific to the undiagnosed hypertensive population and cannot be generalized a priori to patients with treated hypertension. Change in retinal arteriolar and venular calibers has been related to different pathophysiological processes for reasons that remain sometime unexplained. The present findings should be further validated by reference to cellular and molecular biological investigations providing further information on changes in human microcirculation. Further longitudinal analyses are needed to assess the determinants of microvascular remodeling evaluated by retinal vessels.

\section{CONCLUSION}

In never-treated HT patients, reduced CRAE and CRVE were associated with cardiac and renal preclinical damage: LVH and albuminuria. Retinal vascular caliber measured by an accessible, cost-effective, noninvasive, nonmydriatic, fast semi-automated procedure could be useful in the early detection of high-risk HT. Retinal, cardiac, and kidney features could share similar determinants of early damage. The natural history of microvascular remodeling and its pathophysiological determinants remains to be investigated in larger longitudinal studies.

\section{PERSPECTIVE}

In the present study among hypertensive never treated subject, reduced arteriolar and venular retinal caliber was associated with left ventricular hypertrophy and increased albuminuria. Retinal vascular caliber measured by noninvasive fast semi-automated procedure could be useful in the early detection of high-risk hypertensive patients.

\section{CONFLICT OF INTEREST}

There are no conflicts of interest.

\section{REFERENCES}

1. Levy D, Garrison RJ, Savage DD, et al. Prognostic implications of echocardiographically determined left ventricular mass in the Framingham Heart Study. N Engl J Med. 1990;322:1561-1566.
2. Koren MJ, Devereux RB, Casale PN, et al. Relation of left ventricular mass and geometry to morbidity and mortality in uncomplicated essential hypertension. Ann Intern Med. 1991;114:345-352.

3. Weir MR. Microalbuminuria and cardiovascular disease. Clin J Am Soc Nephrol. 2007;2:581-590.

4. Redon J, Williams B. Microalbuminuria in essential hypertension: redefining the threshold. J Hypertens. 2002;20:353-355.

5. Jager A, Kostense PJ, Ruhé HG, et al. Microalbuminuria and peripheral arterial disease are independent predictors of cardiovascular and all-cause mortality, especially among hypertensive subjects: five-year follow-up of the Hoorn Study. Arterioscler Thromb Vasc Biol. 1999;19:617-624.

6. Klag MJ, Whelton PK, Randall BL, et al. Blood pressure and end-stage renal disease in men. N Engl J Med. 1996;334:13-18.

7. Fesler P, Ribstein J, du Cailar G, Mimran A. Determinants of cardiorenal damage progression in normotensive and never-treated hypertensive subjects. Kidney Int. 2005;67:1974-1979.

8. de Leeuw PW, Ruilope LM, Palmer CR, et al. Clinical significance of renal function in hypertensive patients at high risk: results from the INSIGHT trial. Arch Intern Med. 2004;164:2459-2464.

9. Ikram MK, de Jong FJ, Bos MJ, et al. Retinal vessel diameters and risk of stroke: the Rotterdam Study. Neurology. 2006;66:1339-1343.

10. Hubbard LD, Brothers RJ, King WN, et al. Methods for evaluation of retinal microvascular abnormalities associated with hypertension/sclerosis in the Atherosclerosis Risk in Communities Study. Ophthalmology. 1999;106:2269-2280.

11. Wong TY, Mitchell P. Hypertensive retinopathy. N Engl J Med. 2004;351:2310-2317.

12. Sun C, Liew G, Wang JJ, et al. Retinal vascular caliber, blood pressure, and cardiovascular risk factors in an Asian population: the Singapore Malay Eye Study. Invest Ophthalmol Vis Sci. 2008;49:1784-1790.

13. Safar ME, Levy BI, Struijker-Boudier H. Current perspectives on arterial stiffness and pulse pressure in hypertension and cardiovascular diseases. Circulation. 2003;107:2864-2869.

14. Laurent $\mathrm{S}$, Boutouyrie $\mathrm{P}$, Asmar R, et al. Aortic stiffness is an independent predictor of all-cause and cardiovascular mortality in hypertensive patients. Hypertension. 2001;37:1236-1241.

15. Longstreth WT, Manolio TA, Arnold A, et al. Clinical correlates of white matter findings on cranial magnetic resonance imaging of 3301 elderly people. The Cardiovascular Health Study. Stroke J Cereb Circ. 1996;27:1274-1282.

16. de Leeuw F-E, de Groot JC, Oudkerk M, et al. Hypertension and cerebral white matter lesions in a prospective cohort study. Brain J Neurol. 2002;125:765-772.

17. Wang JJ, Liew G, Klein R, et al. Retinal vessel diameter and cardiovascular mortality: pooled data analysis from two older populations. Eur Heart J. 2007;28:1984-1992.

18. McGeechan K, Liew G, Macaskill P, et al. Meta-analysis: retinal vessel caliber and risk for coronary heart disease. Ann Intern Med. 2009:151:404-413.

19. McGeechan K, Liew G, Macaskill P, et al. Prediction of incident stroke events based on retinal vessel caliber: a systematic review and individual-participant meta-analysis. Am J Epidemiol. 2009;170:1323-1332.

20. Tsioufis C, Vezali E, Tsiachris D, et al. Left ventricular hypertrophy versus chronic kidney disease as predictors of cardiovascular events in hypertension: a Greek 6-year-follow-up study. J Hypertens. 2009;27:744-752.

21. Tikellis G, Arnett DK, Skelton TN, et al. Retinal arteriolar narrowing and left ventricular hypertrophy in African Americans. The Atherosclerosis Risk in Communities (ARIC) study. Am J Hypertens. 2008;21: 352-359.

22. Cheung N, Bluemke DA, Klein R, et al. Retinal arteriolar narrowing and left ventricular remodeling: the multi-ethnic study of atherosclerosis. J Am Coll Cardiol. 2007;50:48-55.

23. Ooi QL, Tow FKN-FH, Deva R, et al. The microvasculature in chronic kidney disease. Clin J Am Soc Nephrol. 2011;6:1872-1878. 
24. Baumann M, Burkhardt K, Heemann U. Microcirculatory marker for the prediction of renal end points: a prospective cohort study in patients with chronic kidney disease stage 2 to 4 . Hypertension. 2014;64:338-346.

25. Daien V, Kawasaki R, Villain $M$, et al. Retinal vascular caliber is associated with renal function in apparently healthy subjects. Acta Ophthalmol. 2013;91:e283-288.

26. Mitchell P, Liew G, Rochtchina E, et al. Evidence of arteriolar narrowing in low-birth-weight children. Circulation. 2008;118:518-524.

27. Liew G, Wang JJ, Duncan BB, et al. Low birthweight is associated with narrower arterioles in adults. Hypertension. 2008;51:933-938.

28. Daien V, Carriere I, Kawasaki R, et al. Malnutrition and retinal vascular caliber in the elderly: the POLA study. Invest Ophthalmol Vis Sci. 2014;55:4042-4049.

29. Kawasaki R, Wang JJ, Rochtchina E, et al. Cardiovascular risk factors and retinal microvascular signs in an adult Japanese population: the Funagata Study. Ophthalmology. 2006;113:1378-1384.

30. Wong TY, Klein R, Klein BEK, et al. Retinal vessel diameters and their associations with age and blood pressure. Invest Ophthalmol Vis Sci. 2003;44:4644-4650.

31. Wong TY, Islam FMA, Klein R, et al. Retinal vascular caliber, cardiovascular risk factors, and inflammation: the multi-ethnic study of atherosclerosis (MESA). Invest Ophthalmol Vis Sci. 2006;47:2341-2350.

32. Daien V, Carriere I, Kawasaki R, et al. Retinal vascular caliber is associated with cardiovascular biomarkers of oxidative stress and inflammation: The POLA Study. PLoS ONE. 2013;8:e71089.

33. Xing C, Klein BEK, Klein R, et al. Genome-wide linkage study of retinal vessel diameters in the Beaver Dam Eye Study. Hypertension. 2006;47:797-802.

34. Cuspidi C, Meani S, Valerio C, et al. Prevalence and correlates of advanced retinopathy in a large selected hypertensive population. The Evaluation of Target Organ Damage in Hypertension (ETODH) study. Blood Press. 2005;14:25-31.

35. Shigematsu $Y$, Hamada $M$, Mukai $M$, et al. Clinical evidence for an association between left ventricular geometric adaptation and extracardiac target organ damage in essential hypertension. J Hypertens. 1995;13:155-160.

36. Dahlöf B, Stenkula S, Hansson L. Hypertensive retinal vascular changes: relationship to left ventricular hypertrophy and arteriolar changes before and after treatment. Blood Press. 1992;1:35-44.

37. Cuspidi C, Meani S, Salerno M, et al. Retinal microvascular changes and target organ damage in untreated essential hypertensives. $J$ Hypertens. 2004;22:2095-2102.

38. Grosso A, Rabbia F, Fea A, et al. Comparison between generalized retinal arteriolar narrowing and left ventricular mass in young untreated hypertensive patients. Blood Press. 2006;15:308-312.

39. STROBE checklists 2007. Version 4 as published in Oct/Nov 2007. http://www.strobe-statement.org/index.php?id=available-checklists. Accessed December 30, 2016.

40. Fesler P, Du Cailar G, Ribstein J, Mimran A. Left ventricular remodeling and renal function in never-treated essential hypertension. J Am Soc Nephrol. 2003;14:881-887.

41. Devereux RB, Reichek N. Echocardiographic determination of left ventricular mass in man. Anatomic validation of the method. Circulation. 1977;55:613-618.

42. Sherry LM, Wang JJ, Rochtchina E, et al. Reliability of computerassisted retinal vessel measurement in a population. Clin Exp Ophthalmol. 2002;30:179-182.
43. Knudtson MD, Lee KE, Hubbard LD, et al. Revised formulas for summarizing retinal vessel diameters. Curr Eye Res. 2003;27:143-149.

44. Leung H, Wang JJ, Rochtchina E, et al. Computer-assisted retinal vessel measurement in an older population: correlation between right and left eyes. Clin Exp Ophthalmol. 2003;31:326-330.

45. Nichols WW, O'Rourke MF. Properties of the arterial wall: theory. In: CRC Press, ed. McDonalds Blood Flow in Arteries, 5th edn. London: Hodder Arnold;2005:49-65.

46. Nichols WW, O'Rourke MF. Wave reflections. In: CRC Press, ed. McDonaldsBlood FlowinArteries, 5th edn. London:HodderArnold;2005: 193-213.

47. Wilkinson IB, Fuchs SA, Jansen IM, et al. Reproducibility of pulse wave velocity and augmentation index measured by pulse wave analysis. $J$ Hypertens. 1998;16:2079-2084.

48. Cuspidi C, Macca G, Michev I, et al. Left ventricular concentric remodelling and extracardiac target organ damage in essential hypertension. $J$ Hum Hypertens. 2002;16:385-390.

49. Wong TY, Coresh J, Klein R, et al. Retinal microvascular abnormalities and renal dysfunction: the atherosclerosis risk in communities study. J Am Soc Nephrol. 2004;15:2469-2476.

50. Edwards MS, Wilson DB, Craven TE, et al. Associations between retinal microvascular abnormalities and declining renal function in the elderly population: the Cardiovascular Health Study. Am J Kidney Dis. 2005;46:214-224.

51. Sabanayagam C, Shankar A, Koh D, et al. Retinal microvascular caliber and chronic kidney disease in an Asian population. Am J Epidemiol. 2009;169:625-632.

52. Katsi V, Vlachopoulos C, Souretis G, et al. Association between retinal microcirculation and aortic stiffness in hypertensive patients. Int $J$ Cardiol. 2012;157:370-373.

53. Lin F, Zhu P, Huang F, et al. Aortic stiffness is associated with the central retinal arteriolar equivalent and retinal vascular fractal dimension in a population along the southeastern coast of China. Hypertens Res. 2015;38:342-348.

54. Triantafyllou A, Anyfanti P, Gavriilaki E, et al. Association between retinal vessel caliber and arterial stiffness in a population comprised of normotensive to early-stage hypertensive individuals. Am J Hypertens. 2014;27:1472-1478.

55. Daien V, Duny Y, Ribstein J, et al. Treatment of hypertension with renin-angiotensin system inhibitors and renal dysfunction: a systematic review and meta-analysis. Am J Hypertens. 2012;25:126-132.

56. Thom S, Stettler C, Stanton A, et al. Differential effects of antihypertensive treatment on the retinal microcirculation: an AngloScandinavian cardiac outcomes trial substudy. Hypertension. 2009;54: 405-408.

57. Leung H, Wang JJ, Rochtchina E, et al. Relationships between age, blood pressure, and retinal vessel diameters in an older population. Invest Ophthalmol Vis Sci. 2003;44:2900-2904. 